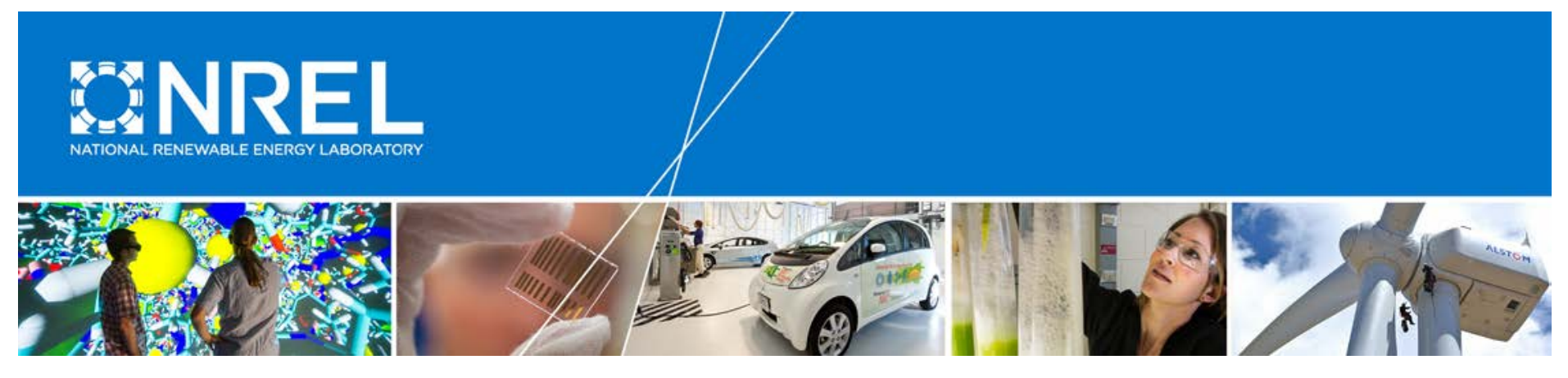

\title{
Short-Term Forecasting of Inertial Response from a Wind Power Plant
}

\section{Preprint}

Eduard Muljadi, Vahan Gevorgian, and Andy Hoke National Renewable Energy Laboratory

To be presented at the 2016 IEEE Energy Conversion Congress and Exposition

Milwaukee, Wisconsin

September 18-22, 2016

(C) 2016 IEEE. Personal use of this material is permitted. Permission from IEEE must be obtained for all other uses, in any current or future media, including reprinting/republishing this material for advertising or promotional purposes, creating new collective works, for resale or redistribution to servers or lists, or reuse of any copyrighted component of this work in other works.

NREL is a national laboratory of the U.S. Department of Energy Office of Energy Efficiency \& Renewable Energy Operated by the Alliance for Sustainable Energy, LLC

This report is available at no cost from the National Renewable Energy Laboratory (NREL) at www.nrel.gov/publications.

\section{Conference Paper}

NREL/CP-5D00-66395

September 2016 


\section{NOTICE}

The submitted manuscript has been offered by an employee of the Alliance for Sustainable Energy, LLC (Alliance), a contractor of the US Government under Contract No. DE-AC36-08GO28308. Accordingly, the US Government and Alliance retain a nonexclusive royalty-free license to publish or reproduce the published form of this contribution, or allow others to do so, for US Government purposes.

This report was prepared as an account of work sponsored by an agency of the United States government. Neither the United States government nor any agency thereof, nor any of their employees, makes any warranty, express or implied, or assumes any legal liability or responsibility for the accuracy, completeness, or usefulness of any information, apparatus, product, or process disclosed, or represents that its use would not infringe privately owned rights. Reference herein to any specific commercial product, process, or service by trade name, trademark, manufacturer, or otherwise does not necessarily constitute or imply its endorsement, recommendation, or favoring by the United States government or any agency thereof. The views and opinions of authors expressed herein do not necessarily state or reflect those of the United States government or any agency thereof.

This report is available at no cost from the National Renewable Energy Laboratory (NREL) at www.nrel.gov/publications.

Available electronically at SciTech Connect http:/www.osti.gov/scitech

Available for a processing fee to U.S. Department of Energy and its contractors, in paper, from:

U.S. Department of Energy

Office of Scientific and Technical Information

P.O. Box 62

Oak Ridge, TN 37831-0062

OSTI http://www.osti.gov

Phone: 865.576.8401

Fax: 865.576.5728

Email: reports@osti.gov

Available for sale to the public, in paper, from:

U.S. Department of Commerce

National Technical Information Service

5301 Shawnee Road

Alexandria, VA 22312

NTIS http://www.ntis.gov

Phone: 800.553 .6847 or 703.605 .6000

Fax: 703.605.6900

Email: orders@ntis.gov 


\title{
Short-Term Forecasting of Inertial Response from a Wind Power Plant
}

\author{
E. Muljadi, Fellow, IEEE, V. Gevorgian, Member, IEEE, and A. Hoke, Member, IEEE
}

\begin{abstract}
The total inertia stored in all rotating masses (synchronous generators, induction motors, etc.) connected to a power system grid is an essential force that keeps the system stable after disturbances. Power systems have been experiencing reduced inertia during the past few decades [1]. This trend will continue as the level of renewable generation (e.g., wind and solar) increases.

Wind power plants (WPPs) and other renewable power plants with power electronic interfaces are capable of delivering frequency response (both droop and/or inertial response) by a control action; thus, the reduction in available online inertia can be compensated by designing the plant control to include frequency response. The source of energy to be delivered as inertial response is determined by the type of generation (wind, photovoltaic, concentrating solar power, etc.) and the control strategy chosen. The importance of providing ancillary services to ensure frequency control within a power system is evidenced from many recent publications with different perspectives (manufacturer, system operator, regulator, etc.) [2]-[6].

This paper is intended to provide operators with a method for the real-time assessment of the available inertia of a WPP. This is critical to managing power system stability and the reserve margin. In many states, modern WPPs are required to provide ancillary services (e.g., frequency regulation via governor response and inertial response) to the grid. This paper describes the method of estimating the available inertia and the profile of the forecasted response from a WPP.
\end{abstract}

Index Terms - ancillary service, frequency response, inertial response, variable generation, wind turbine generator, wind power plant.

\section{INTRODUCTION}

A THOUGH Type 1 and Type 2 wind turbine generators (WTGs) were used in the early days of wind generation, modern WTGs are Type 3 and Type 4 . In this paper, only the latter two types will be analyzed because they are relevant to the current and future situations.

Physical diagrams of Type 3 and Type 4 WTGs are shown in Fig. 1. Both are equipped with a power converter, which allows for the flexible, independent, and instantaneous control of real and reactive power.

\section{A. Wind Turbine Generators (WTGs)}

In principle, a WTG converts aerodynamic power into electric power. The aerodynamic power is produced by passing wind through the blades, which in turn drives the rotary shaft. The rotational speed of the shaft is limited because the tip of the blade can produce a loud jet noise when it travels at a high speed. Thus, the larger the turbine is, the longer the blades are, and the lower the rotational speed is to suppress the jet noise.
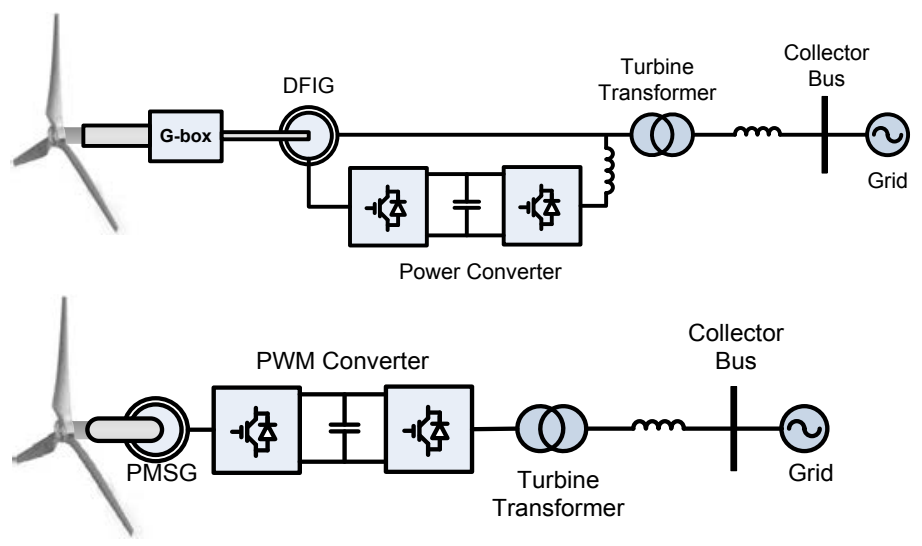

a) Doubly-fed induction generator (Type 3 WTG)

b) Full power conversion (Type 4 WTG)

Fig. 1. Variable-speed WTGs

Because the rotational speed of the blades is very slow, it is customary to use the gearbox to increase the rotational speed to match the generator speed. The size of the generator is inversely proportional to the rotational speed. The higher the rotational speed of the generator is, the smaller and lighter the generator is. Thus, it is to be expected that the size of the generator is very large for a direct-drive WTG system. The choice of using the gearbox or the direct-drive system depends on the balance between the technical and economic advantages.

\section{1) Available Aerodynamic (Wind) Power}

The available aerodynamic power of a WTG can be computed from the wind speed and the wind turbine dimension as:

$$
P_{\text {aero }}=0.5 \rho \pi R^{2} C_{p} V^{3}
$$

where $\mathrm{R}$ is the blade radius, $\rho$ is the air density, $\mathrm{V}$ is the wind speed, and $\mathrm{C}_{\mathrm{p}}$ is the performance coefficient of the WTG. The aerodynamic characteristic of the WTG is shown below, and it is affected by the pitch angle of the blades.

The tip speed ratio (TSR) is defined as the ratio of the linear speed of the tip of the blade to the wind speed:

$$
T S R=\frac{\omega R}{V}
$$

where, $\omega$, the rotational speed, is the rotational speed of the blade. As shown in Fig. 2, at any blade pitch angle, there is a 
specific TSR that has a maximum operating $\mathrm{Cp}$. At blade pitch angle $0^{\circ}$, this TSR corresponds to $\mathrm{TSR}_{\text {cp_max }}=10, \mathrm{C}_{\mathrm{pmax}}=0.52$.

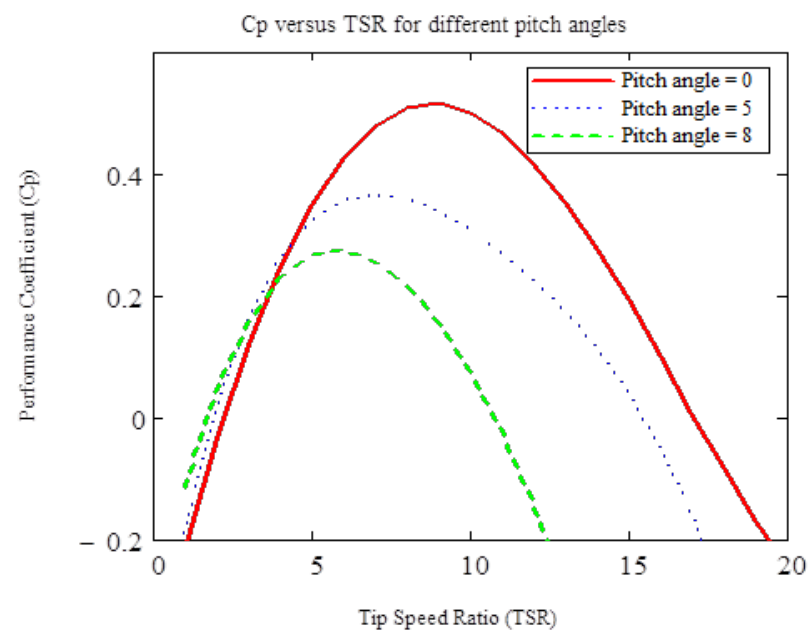

Fig. 2. Performance coefficient of the WTG

Aerodynamic Power vs Rotor Speed in p.u.

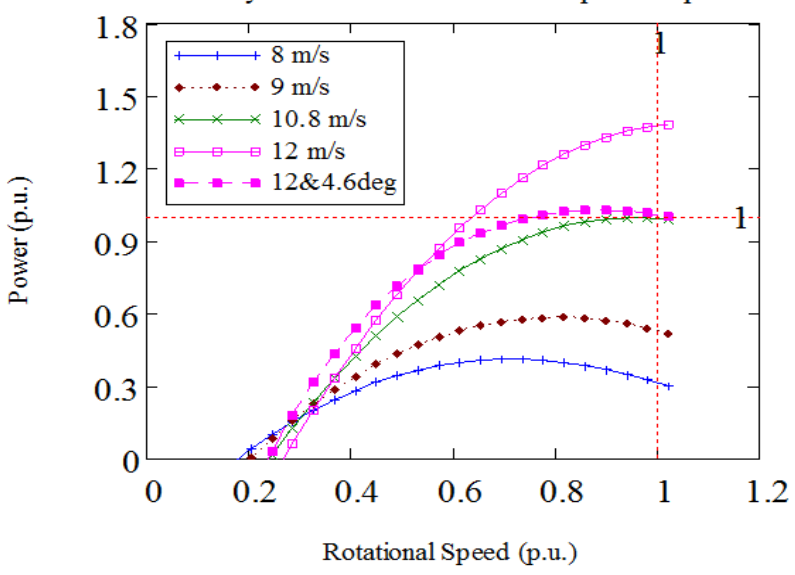

Fig. 3. Aerodynamic power of a WTG as a function of the rotational speeds for different wind speeds

Under normal conditions, the WTG is operated at its maximum power coefficient to generate the maximum power available from a wind power plant (WPP) for a given wind speed. The maximum aerodynamic power can be computed as:

$$
P_{\text {aero_max }}=0.5 \rho \pi R^{2} C_{\text {pmax }} V^{3}
$$

Fig. 3 shows the aerodynamic power as a function of the rotational speed of the WTG. The pitch control is activated only above the rated wind speeds to limit the rotational speed at its rated value. Below rated wind speeds, the pitch angle is set to an optimum value (e.g., $0^{\circ}$ ). As shown in Fig. 3, the rated wind speed of the WTG is $10.8 \mathrm{~m} / \mathrm{s}$. At the wind speed of $12 \mathrm{~m} / \mathrm{s}$, the aerodynamic output power (shown as the pink line with the outlined square symbols) exceeds the rated power of the electrical generator and the associated power converter; thus, the blade pitch must be activated to reduce the aerodynamic power to rated power. In this case, the pitch angle necessary to limit the output aerodynamic power to its rated value is $4.6^{\circ}$ (shown as the pink line with the solid square symbols). The pitch is usually controlled to limit the rotational speed to its rated speed, $\omega=1.0$ p.u. If the pitch angle stays at $0^{\circ}$, the aerodynamic power will stay higher than its generator rated power. This can cause the rotor speed to increase very quickly and result in a rotor runaway problem.

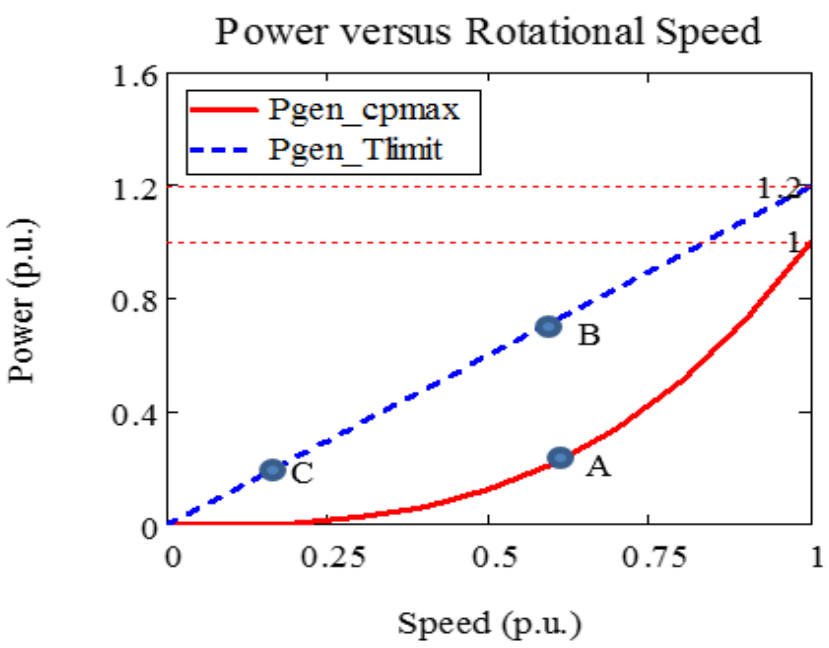

Fig. 4. Electrical output power of a WTG as a function of the rotational speeds for normal $\mathrm{C}_{\mathrm{pmax}}$ and $\mathrm{T}_{\text {limit }}$ operations

\section{2) Actual Electrical Power Delivered to the Grid}

The actual power delivered to the grid is shaped by the power converter controlling the WTG. From the point of view of the power generation, the actual power that can be delivered to the grid depends on the available aerodynamic power minus the losses.

The actual output power of the WTG is shaped by the power converter, and it can be computed by operating the WTG at maximum power. Substituting the wind speed with the rotational speed, the following equation can be used to shape the generator output based on the rotational speed input, $\omega$ :

$$
P_{\text {GEN_cpmax }}=P_{\text {aero_max }}=P_{\text {rated }} \omega^{3}
$$

where: $P_{\text {rated }}=0.5 \rho \pi R^{2} C_{\text {pmax }}\left[\frac{R}{T S R_{\text {cpmax }}}\right]^{3}$

The power converter and generator can be used to harvest the maximum aerodynamic power. Fig. 4 shows the generator output power in the solid line labeled $\mathrm{P}_{\mathrm{cpmax}}$, which is a cube function of the rotational speed. $\mathrm{P}_{\mathrm{GEN} \_ \text {cpmax }}$ is used to control the WTG under normal operation, thus maximizing the aerodynamic efficiency of the turbine. Fig. 4 also shows the generator output power when its output is controlled to maintain the generator torque constant at its torque limit. Note that the generator is usually controlled to produce torque at rated flux. Because the torque is proportional to the flux and the stator current, this implies that the torque limit also 
dictates the current limit of the converter design. This dashed line is a representation of the generator operation at the upper limit for the current-carrying capability of the power semiconductor switches (e.g., insulated-gate bipolar transistor). Maintaining operations below the torque limit is important to protect the gearbox from overstressed conditions that may shorten its lifetime. In this example, it is assumed that the generator can be operated at the torque level of 1.2 p.u., but this value depends on the manufacturer's design.

As an example, suppose that the WTG is originally operated at Point A. When the inertial response is commanded, the generator operating point will move from A to $\mathrm{B}$; thus, a power boost (AB) is delivered to the grid. The generator output power is then operated along the line $\mathrm{BC}$, thus operating at maximum torque because the maximum possible aerodynamic power at any rotational speed follows the red solid line. The generator power during the inertial response (along $\mathrm{BC}$ ) is higher than the available aerodynamic power; thus, the rotational speed decreases while releasing kinetic energy. The area under the dashed line $\left(T_{\text {limit }}\right.$ operation) is considered the safe operating area for the generator and power converter-i.e., the power converter and generator are designed by the manufacturer to be able to operate in this region without causing overheating/overtemperatures or permanent damage to the power semiconductor switches or the winding insulation of the electric generator. The capability to provide ancillary services is available upon request from most modern turbine manufacturers [7].

\section{IMPLEMENTING INERTIAL RESPONSE FORECASTING}

System inertial frequency response estimation can be found in [8], and [9] presented level the inertia of a WPP based on synchrophasor measurements. In this paper, instead of estimating the size of the inertia, we forecast the inertial response given a specific inertial control algorithm. Other methods of inertial control algorithms can be found in [10][12]. Implementing inertial response forecasting requires sampling the output power, $\mathrm{P}_{\text {gen }}$, from each WTG. From the sampled $P_{\text {gen }}$, the rest are computed. In this paper, the sampling is taken every 5 seconds. The inertial response prediction will be presented as the time series output of the generator or WPP for the next 20 seconds based on the 5second-interval sampled generator output power. The resulting plot is displayed and continuously refreshed every 5 or 20 seconds (programmable). The computation is implemented in MATLAB.

\section{A. Input Data Required to Compute the Prediction}

There are many ways to extract kinetic energy from the blades; the method written here is only one. It is assumed that the WPP consists of identical turbines of the same size, type, manufacturer, and control algorithms. The input data required to compute the short-term forecast of the initial response is mainly the generator output power $\left(\mathrm{P}_{\mathrm{gen}}\right)$ at each sampling time. Similarly, a logical variable ARW_Flag to signify that the WTG operation is above rated wind speed is needed every sampling time. ARW_flag $=1$ if the wind speed is above rated; it is set to zero otherwise. ARW_flag can also be set by observing the pitch angle. A pitch angle $>0^{\circ}$ signifies aboverated wind speed operation. For above-rated operation, an overload maximum time should be enforced according to the manufacturer's standard. For example, $\Delta \mathrm{T}_{\text {ovld }}$ is a onetime input to the program to ensure that the operation in the overload mode ( $\mathrm{T}_{\text {limit }}$ operation) does not exceed the maximum allowable time $\left(\Delta \mathrm{T}<\Delta \mathrm{T}_{\text {ovld }}\right)$.

The performance coefficient of the WTG, $\mathrm{C}_{\mathrm{p}}(\lambda)$, of the turbine used can be expressed by the nonlinear function of the TSR $(\lambda=\omega \mathrm{R} / \mathrm{V})$. The performance coefficient can be represented by a polynomial equation; thus, these polynomial coefficients are precomputed constants and onetime inputs to the program.

$$
\mathrm{C}_{\mathrm{p}}(\lambda)=\mathrm{c}_{5} \lambda^{5}+\mathrm{c}_{4} \lambda^{4}+\mathrm{c}_{3} \lambda^{3}+\mathrm{c}_{2} \lambda^{2}+\mathrm{c}_{1} \lambda+\mathrm{c}_{0}
$$

Other required input constants are the blade radius, $\mathrm{R}$; air density, $\mathrm{p}$; total inertia, $\mathrm{J}$; power, $\mathrm{P}_{\text {rated }}$; and maximum allowable torque, $\mathrm{T}_{\text {limit. }}$.

\section{B. Computing Aerodynamic Power, $P_{\text {aero }}$}

The initial average wind speed can be computed based on the measured generator output power and the rated wind speed.

$$
v_{w \_ \text {init }}=v_{w \_ \text {rated }}\left[\frac{P_{\text {gen_init }}}{P_{\text {rated }}}\right]^{1 / 3}
$$

where

$v_{w_{-} \text {rated }}=$ rated average wind power

$v_{w_{-} \text {init }}=$ average wind power at the beginning of the 5 -second cycle

$P_{\text {gen } \_ \text {init }}=$ generator output power at the beginning of the 5second cycle

$P_{\text {gen_rated }}=$ rated power of the wind turbine

The above formula can calculate the wind speed prediction below rated speed; however, it fails to compute the average wind speed above rated speed. This is because when the wind turbine operates above rated wind speeds, the pitch controller will adjust the pitch angle to keep the rotational speed from exceeding the rated speed. The generator output power is commanded to follow the cube function of the rotational speed; thus, the generator output power will never exceed the rated power. By measuring only the generator output power, we can compute only the below-rated wind speed. Another input data point at each sampling should be acquired in addition to the generator output power.

With the assumption that the wind speed is constant for the duration between samples ( 5 seconds), the TSR $(\lambda=\omega \mathrm{R} / \mathrm{V})$ and the performance coefficient $\mathrm{C}_{\mathrm{p}}(\lambda)$ can be computed as the computed rotational speeds change. The aerodynamic power can be computed from (1). The computed aerodynamic power is relevant only below rated wind speed operation because above rated wind speed operation, the rotor speed will always be limited to its rated value by the pitch controller. 


\section{Computing Electrical Power, $P_{\text {gen }}$}

The generator output power, $\mathrm{P}_{\text {gen }}$, is acquired every sampling time. In between samples, the electrical output power of the WTG is computed to predict the behavior of the wind turbine. Depending on the nature of the operationwhether the WTG is operating under normal conditions or operating in inertial-response mode - the generator power can be computed as follows:

Normal conditions, before and after activation of the inertial response:

$$
P_{\text {gen }}=P_{\text {rated }} \omega^{3}
$$

During activation of the inertial response:

$$
P_{\text {gen }}=T_{\text {limit }} \omega
$$

\section{Computing Rotational Speeds}

Estimating the rotational speed can be computed by first checking the status of the above-rated wind (ARW) flag. If the operation is above rated speed, the initial rotational speed is at rated $\left(\omega_{\mathrm{t} \_ \text {init }}=\omega_{\text {rated }}\right.$ then, ARW flag $\left.=1\right)$. Otherwise, the initial rated speed is at a point lower than the rated speed-e.g., Point A (Fig. 4) — and it can be computed by (4).

$$
\omega_{t \_ \text {init }}=\left[\frac{P_{\text {gen_init }}}{P_{\text {rated }}}\right]^{1 / 3}
$$

The end of the inertial response activation is when the generator output decreases to the initial output power (as shown in the previous section, $\mathrm{P}_{\mathrm{C}}=\mathrm{P}_{\mathrm{A}}$ ). We use the rotational speed to signal the end of the inertial response (when the rotational speed reaches the rotor speed, $\omega_{\mathrm{t} \_ \text {end }}$, at Point C). It can be computed from the torque limit operation.

$$
\omega_{t_{-} \text {end }}=\frac{P_{\text {gen_init }}}{T_{\text {Limit }}}
$$

Thus, the turbine speed operating range is between $\omega_{t_{-} \text {init }}$ at Point $\mathrm{A}$ and $\omega_{\mathrm{t} \_ \text {end }}$ at Point $\mathrm{C}$. Between the samplings, calculating the rotational speed can be computed as:

$$
\omega_{t}=\omega_{t_{-} \text {init }}+\frac{1}{J} \int \frac{\left(P_{\text {aero }}-P_{g e n}\right)}{\omega_{t}} d t
$$

\section{E. Wind Turbine Generator Perspective}

In this subsection, predicting the inertial response of a WTG will be tested for different sets of wind speeds. The input at each sampling time is given in Table I. The forecasted inertial responses for the three wind speeds listed in Table I are shown in Fig. 5. Fig. 5 (a) shows the output power of the three turbines (per unit), with the initial output given Table 1. Fig. 5 (b) shows the output power at the point of interconnection (POI), which is the sum of the inertial responses from all the turbines.

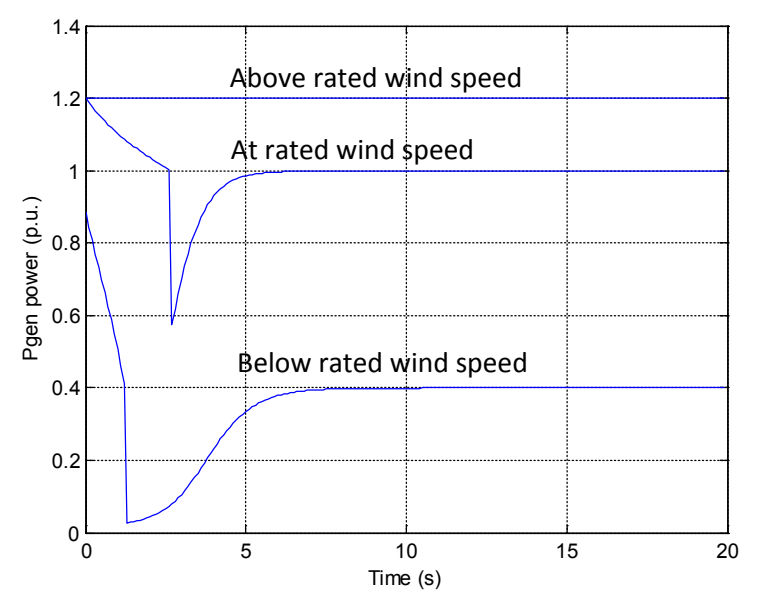

(a) Output power at different wind speeds

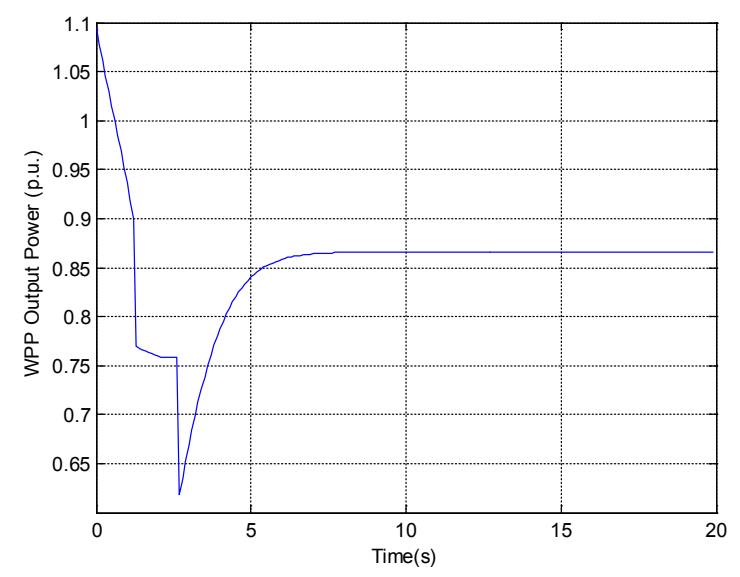

(b) Output power at the POI of the WPP formed by the three turbines in (a)

Fig. 5. Forecasted inertial response

Table I. Initial Output Power of the Generator

\begin{tabular}{|l|c|c|c|}
\hline WTG \# & $\# 1$ & $\# 2$ & $\# 3$ \\
\hline ARW_Flag & 0 & 0 & 1 \\
\hline $\mathrm{P}_{\text {gen }}$ (p.u.) & 0.4 & 1.0 & 1.0 \\
\hline
\end{tabular}

\section{F. Wind Power Plant Perspective}

A real WPP covers a very large area. In addition, the landscape may not necessarily be flat; some WPPs are on hilly ground. Thus, there is diversity of the wind resource within WPPs; the wind speed at a single turbine at one corner of a WPP may be different from the wind speed experienced by a wind turbine at another corner. Predicting the inertial response of a WPP must include the diversity within the plant.

To test the inertial response forecast, we include an example of a WPP with 20 turbines with initial outputs as shown in Fig. 6 (a). The corresponding forecasted output of the WPP for the duration of the period chosen ( 20 seconds) is shown in Fig. 6 (b). Note that the total response at the POI is much smoother than the individual output power of the single turbine shown in Fig. 5 (b). 


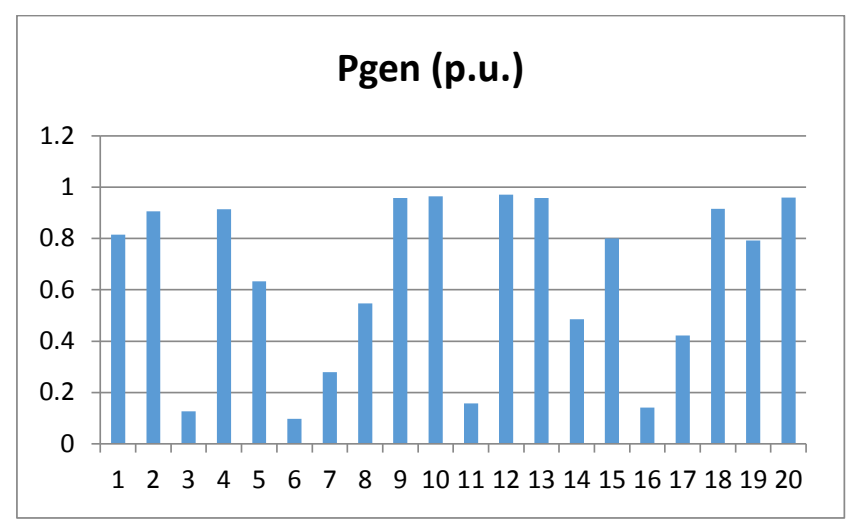

(a) Assumed initial output power of 20 WTGs

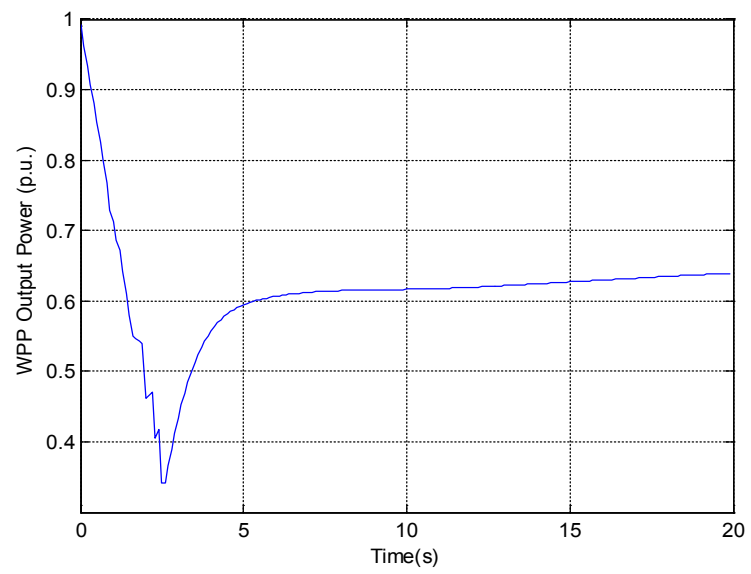

(b) Output power at the POI formed by the 20 WTGs in (a)

Fig. 6. Initial output power of the WTGs and the forecasted inertial response of the WPP for 20 seconds of observation

\section{CONCLUSIONS}

The evolution of the capabilities and requirements of WTG to support grid integration that lead to inertial response has been presented. This was then followed by a description of the general characteristics of WTGs, including the mechanical and electrical loading paths that need to be considered when designing WTGs to fulfill the capabilities required by independent system operators, regional reliability organizations, wind turbine developers, and utilities.

The methods of deploying inertial response and the implications of various methods chosen as the inertial response control strategy on the power converter, gearbox, and generator design requirements are beyond the scope of this paper. The proposal to limit the torque limit and output current is intended to limit the potential damage and integrity of the mechanical structure (e.g., gearbox) and the power electronic switches. The inertial response of WTGs for different operating wind speeds and their contributions to the grid at the levels of the WTGs and at the WPPs have also been presented.

The ability to look ahead of the available inertial response from a large WPP for the next 5 to 20 seconds is critical for the system operator. This will inform the instantaneous margin available for inertial response deployment during critical times (loss of generations causing frequency dips) that may jeopardize the reliability of a power system and thus ensure the dynamic stability of the power system.

\section{ACKNOWLEDGMENT}

This work was supported by the U.S. Department of Energy under Contract No. DE-AC36-08-GO28308 with the National Renewable Energy Laboratory.

\section{REFERENCES}

[1] J. W. Ingleson and E. Allen, "Tracking the Eastern Interconnection frequency governing characteristic," presented at the 2010 IEEE Power and Energy Society General Meeting, Minneapolis, Minnesota.

[2] E. Muljadi, V. Gevorgian, M. Singh, and S. Santoso, "Understanding inertial and frequency response of wind power plants," presented at the IEEE Symposium on Power Electronics and Machines for Wind Applications, Denver, Colorado, July 16-18. NREL/CP-5500-55335. Golden, CO: National Renewable Energy Laboratory, July 2012.

[3] V. Gevorgian, Y. C. Zhang, and E. Ela, "Investigating the impacts of wind generation participation in interconnection frequency response," IEEE Trans. Sustainable Energy, vol. PP, no. 99, August 2014.

[4] J. H. Eto et al., "Use of frequency response metrics to assess the planning and operating requirements for reliable integration of variable renewable generation," Ernest Orlando Lawrence Berkeley National Laboratory, Berkeley, CA, Tech. Rep., Dec. 2010.

[5] North American Electric Reliability Corporation, "Frequency response initiative report-The reliability role of frequency response," Washington, D.C., Tech. Rep., Oct. 2012.

[6] Federal Energy Regulatory Commission, "BAL-003-1-Frequency response and frequency bias setting," Washington, D.C., March 2013.

[7] N. W. Miller and K. Clark, "Advanced controls enable wind plants to provide ancillary services," in Proc. 2010 IEEE Power and Energy Society General Meeting.

[8] S. Sharma, S. Huang, and N. Sarma, "System inertial frequency response estimation and impact of renewable resources in ERCOT interconnection," in Proc. 2011 IEEE Power and Energy Society General Meeting, pp. 1-6.

[9] Y. Zhang, J. Bank, Y. H. Wan, E. Muljadi, and D. Corbus, "Synchrophasor measurement-based wind plant inertia estimation," preprint, presented at the IEEE Green Technologies Conference, Denver, Colorado, April 4-5, 2013. NREL/CP-5500-57471. Golden, CO: National Renewable Energy Laboratory, May 2013.

[10] M. Kang, K. Kim, E. Muljadi, J.-W. Park, and Y. C. Kang, "Frequency control support of a doubly-fed induction generator based on the torque limit," IEEE Trans. Power Syst., to be published.

[11] J. Lee, E. Muljadi, P. Sorensen, and Y. Kang, "Releasable kinetic energy-based inertial control of a DFIG wind power plant," IEEE Trans. Sustain. Energy, vol. 7, no. 1, pp. 279-288, 2016.

[12] M. Hwang, E. Muljadi, J. W. Park, P. Sorensen, and Y. C. Kang, "Dynamic droop-based inertial control of a doubly-fed induction generator," IEEE Trans. Sustain. Energy, vol. PP, no. 99, pp. 1-10, 2016. 